University of Nebraska - Lincoln

DigitalCommons@University of Nebraska - Lincoln

Faculty Publications: Department of Entomology

1984

\title{
Seedcorn Maggot (Diptera: Anthomyiidae) Reproductive Biology and Techniques for Examining Ovarian Dynamics
}

\author{
L. G. Higley \\ lowa State University, Ihigley1@unl.edu \\ L. P. Pedigo \\ lowa State University
}

Follow this and additional works at: https://digitalcommons.unl.edu/entomologyfacpub

Part of the Entomology Commons

Higley, L. G. and Pedigo, L. P., "Seedcorn Maggot (Diptera: Anthomyiidae) Reproductive Biology and Techniques for Examining Ovarian Dynamics" (1984). Faculty Publications: Department of Entomology. 292.

https://digitalcommons.unl.edu/entomologyfacpub/292

This Article is brought to you for free and open access by the Entomology, Department of at DigitalCommons@University of Nebraska - Lincoln. It has been accepted for inclusion in Faculty Publications: Department of Entomology by an authorized administrator of DigitalCommons@University of Nebraska - Lincoln. 


\title{
Seedcorn Maggot (Diptera: Anthomyiidae) Reproductive Biology and Techniques for Examining Ovarian Dynamics
}

\author{
L. G. HIGLEY AND L. P. PEDIGO
}

Department of Entomology, Iowa State University, Ames, Iowa 50011

\begin{abstract}
J. Econ. Entomol. 77: 1149-1153 (1984)
ABSTRACT We developed techniques for examining ovarian dynamics of the seedcorn maggot, Delia platura (Meigen), and delineated detailed procedures for ovarian dissections and classifications. A three-class ovarian rating system was devised and physiological ages for each class were determined. The preovipositional period was 36 degree-days (DD) in the field and 100 DD in the laboratory. No ovarian development was observed unless females had been given a protein food source. All females with ovarian development had mated.
\end{abstract}

OVARIAN DYNAMICS, or gonadotrophic cycles, have been studied in a number of muscomorphous (cyclorrhaphous) Diptera as a method for determining population age structure and phenology. Anderson (1964) discussed the philosophy and principles behind this approach. At a gross level, females may be classified as having laid a batch of eggs (parous) or as not having oviposited (nulliparous). More refined schemes characterize the degree of ovarian development and ascribe development times to distinct ovarian development classes. The time between ovarian classes can be highly dependent on temperature and nutritional factors.

Despite the potential usefulness of this technique, ovarian dynamics have been examined in relatively few species of the Muscomorpha, and primarily in the Muscidae and Calliphoridae. For example, Anderson (1964) described ovarian development in the muscids Fannia canicularis (L.), Musca domestica L., Muscina stabulans (Fallen), Myospila meditabunda F., Ophyra leucostoma (Wiedemann), Orthellia caesarion (Meigen), and Stomoxys calcitrans (L.), as well as in the calliphorid Calliphora terraenovae (Meigen). Miller and Treece (1968) rated Musca autumnalis DeGeer females as nulliparous, uni-, bi-, or triparous. A 17-class ovarian development system, based on parity and the degree of vitellogenesis, was constructed for Musca vetustissima Walker (TyndaleBiscoe and Hughes 1969). A similar scheme, using 16 ovarian stages, has been developed for Lucilia cuprina (Wiedemann) (Vogt et al. 1974).

Ovarian dynamics in the Anthomyiidae have been examined previously for only one species, the onion maggot, Delia antiqua (Meigen) (Liu et al. 1982). A three-class system was developed for rating onion maggot ovarian development, with classes consisting of newly emerged flies, flies with developing oocytes, and unproductive flies. Developmental times were not determined for these classes, but the classification did allow the discrimination of early second- and third-generation flies.
Some authors (Anderson 1964, Vogt et al. 1974, Woodburn et al. 1978) have pointed out that times associated with ovarian developmental stages usually represented minimum ages. Ovarian development may be delayed by cool temperatures or by nutritional deficiencies, specifically, the lack of a protein meal. Obviously, studies on the ovarian dynamics of a species must consider both temperature and diet, as well as time.

We examined seedcorn maggot (SCM), Delia platura (Meigen) (Diptera: Anthomyiidae), ovarian dynamics in order to develop a procedure for determining SCM population age structure and phenology. Questions regarding SCM reproductive biology were also considered as a part of this examination.

\section{Materials and Methods}

Adult female SCM were sampled in 1982 and 1983 by using two cone traps baited with a mollases-yeast mixture. Traps were located south of Ames, Iowa, and flies were collected every 2 days from early April to mid-July. Adult flies collected in cone traps were taken to the laboratory in clear plastic bags for dissection.

Female SCM of known ovipositional histories were obtained by collecting pupae from soil in the field. Pupae were maintained singly in cups in the laboratory until adults emerged. Adult SCM that emerged were then placed in cages containing water and surcrose or water, sucrose, and yeast. Females were removed from these cages at daily intervals, for 1 week, and dissected. Adults and pupae were maintained in the laboratory at $21^{\circ} \mathrm{C}$ and approximately $85 \% \mathrm{RH}$.

To use SCM ovarian dynamics in population studies, a procedure had to be developed that allowed rapid dissections and identifications of ovarian classes. On most sampling days, between 40 and 80 flies were examined, and on peak days, up to 120 flies were dissected. Flies were killed, identified, and sexed. Females were pinned, ventum 
up, and the ovaries were removed for detailed examination (Fig. 1). Ovaries were placed in $7 \%$ saline solution in cells of a clear glass depression plate. Ovarioles were separated to give a clear view of the pedicels and examined under a dissecting microscope. In 1982, the spermathecae of approximately 100 females were removed, placed on microscope slides with saline, and crushed under cover slips. The spermathecae were examined under a compound microscope for the presence of spermatozoa.

Seedcorn maggot females infected with Entomophthora muscae (Cohn) Freseuius had considerable degeneration of the reproductive system and could not be classified.

A number of problems with or limitations of the dissection procedure were encountered. Collected flies died quickly, especially under high temperatures, and the ovaries of dead flies decayed rapidly. No procedure could be developed a preserve to preserve SCM ovaries for later examination. Freezing destroyed reproductive tissues, and alcohol washed out color, making identifications difficult or impossible. Although maintaining living flies at cool temperatures (above freezing) seemed to prevent further ovarian development, it also produced unacceptably high mortality. Consequently, SCM females had to be dissected within 2 to $3 \mathrm{~h}$ of collection. A further difficulty arose when some SCM females collected in traps had distended guts filled with the molasses bait. If the gut was penetrated during dissection, the reproductive system was tinted yellow from the molasses, but rinsing the ovaries with saline removed this discoloration.

Temperature accumulations between ovarian classes were measured in the laboratory and from field observations. A $3.9^{\circ} \mathrm{C}$ threshold for ovarian development was used, which agreed with our laboratory observations and those of Yathom (1970). Laboratory-reared females of known age were dissected and ovarian development rated. Ratings were determined without prior knowledge of female age in order to preclude possible bias. In 1982 and 1983, the duration of ovarian classes and the preovipositional period also was calculated from field data. Early in the season, when temperatures were low and development protracted, we measured differences between the midpoints of peaks for each ovarian class or between the times when classes disappeared.

\section{Results and Discussion}

Ovarian Development Classes. During 1982, we examined alternative systems for rating SCM ovarian development. Seedcorn maggot females could be separated into nulliparous and parous groups. These classes then could be subdivided on the basis of vitellogenesis or other characteristics. In SCM, after the first batch of eggs was laid, subsequent ovipositions could not be differentiated; conse-

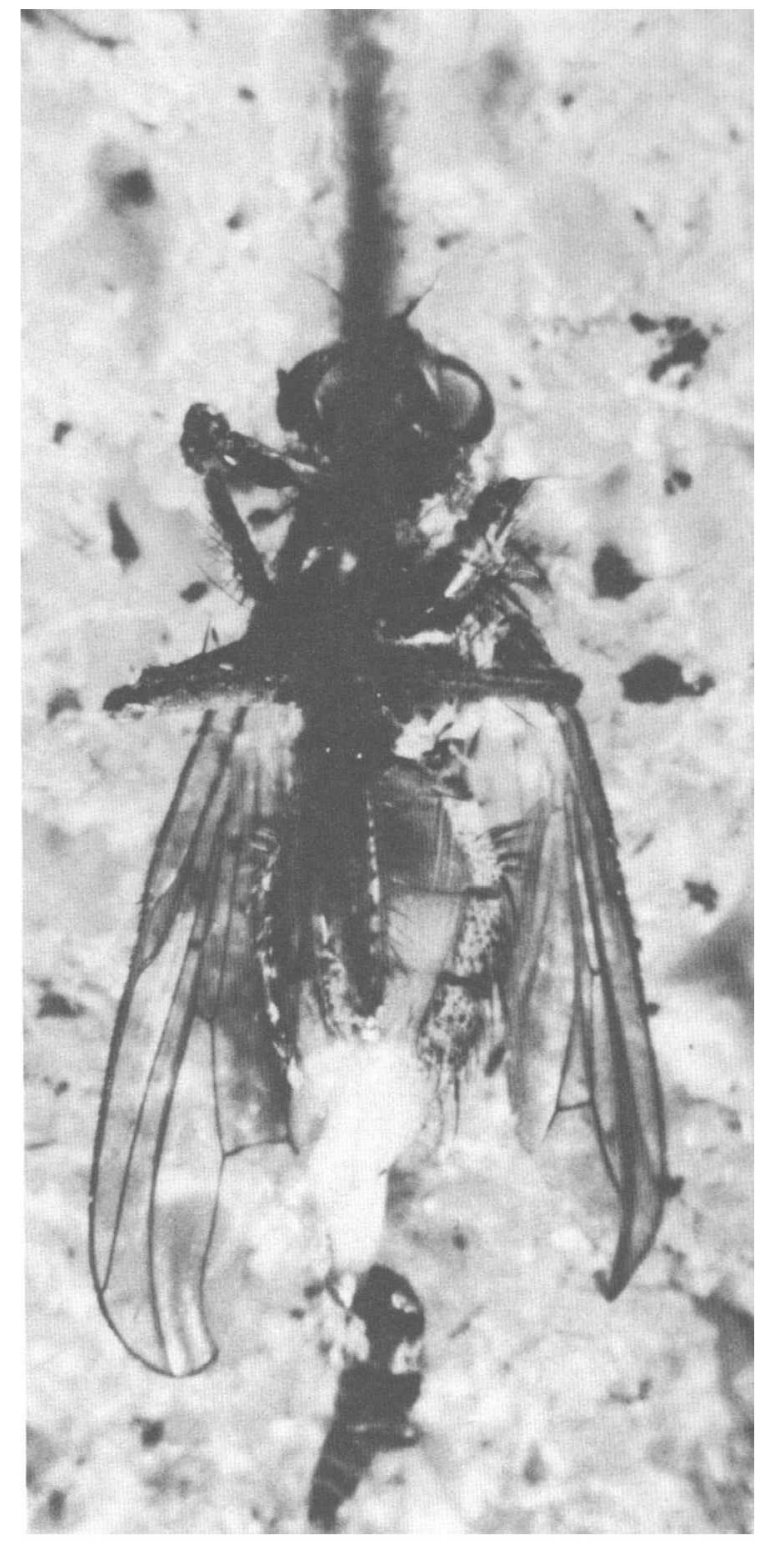

Fig. 1. Removal of ovaries from SCM female.

quently, no meaningful subdivisions of the parous class could be used. Similarly, development in the nulliparous class was so rapid that subdivisions based on the degree of vitellogenesis did not add sufficient information to warrant the substantial effort involved in distinguishing classes. However, newly emerged females could be readily differentiated from nulliparous flies with developing oocytes, so we arrived at a three-class ovarian rating system as follows:

I. Nulliparous (newly emerged). This was usually the easiest class to differentiate and, with experience, could be recognized during the dissections, so complete removal of the ovaries often was unnecessary. Females in this class had extremely 


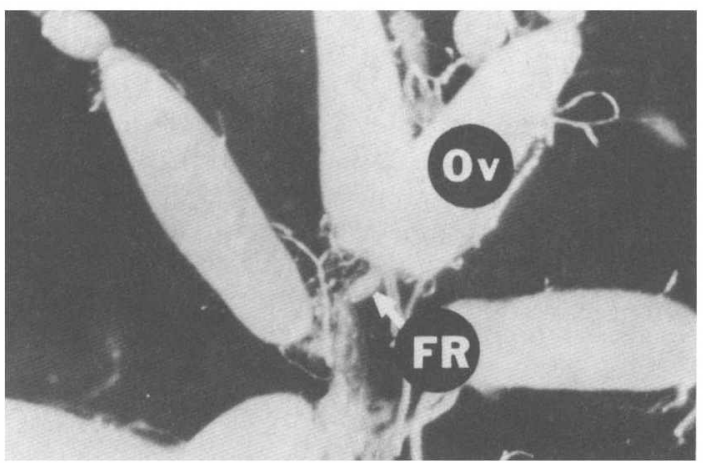

Fig. 2. Ovarioles and follicular relics from a parous female (class III); $\mathrm{Ov}$, ovariole; FR, follicular relic.

small, white ovaries with no indication of any development. In addition, these flies frequently had many small, round, white pupal fat bodies in the haemocoel. Tracheal skeins (knots or balls of tracheae on ovarioles) were difficult to see and this was not a useful character.

II. Nulliparous (developing oocytes). Females in this category had some degree of ovarian development but had never deposited a batch of eggs. Ovarioles were white, and vitellogenesis was observable in the primary oocytes.

III. Parous. Females in this class had oviposited at least once. These flies could be recognized by the presence of a yellow follicular relic in the pedicel at the base of each ovariole (Fig. 2). (Follicular relics are difficult to see because the ovarioles have to be well spread to allow a clear view of the pedicel.) The ovarioles also may take on a slight yellow tint, particularly with older flies. Individual relics from separate ovipositions could not be recognized or counted as a technique for subdividing the parous class.

The two classes of nulliparous flies were rarely confused, but distinctions between nulliparous flies with developing oocytes and parous flies were more difficult. Parous females have follicular relics, clumps of colored tissue in the pedicels of their ovarioles; nulliparous flies lack these follicular relics. When difficulty was encountered in distinguishing this class from the parous class, the fly usually was parous.

Dissections of spermathecae revealed that most class I females were unmated, but in all cases where any degree of ovarian development was discernable, the females had mated. This apparent relationship between mating and ovarian development implies that flies must mate very shortly after emergence and that mating might be a physiological prerequisite to ovarian development.

Reproductive Ages and the Preovipositional Period. In the laboratory, the transition from class I (nulliparous-newly emerged) to class II (nulliparous-developing oocytes) required 2 days or 33.3 degree-days (DD). The transition from class II to
Table 1. Length of the SCM preovipositional period from the literature

\begin{tabular}{llcc}
\hline \multicolumn{1}{c}{ Source } & $\begin{array}{c}\text { Type of } \\
\text { study }\end{array}$ & $\begin{array}{c}\text { Time } \\
\text { (days)- } \\
\text { temp }\left({ }^{\circ} \mathrm{C}\right)\end{array}$ & $\begin{array}{c}\text { DD } \\
\left(3.9^{\circ} \mathrm{C}\right. \\
\text { threshold })\end{array}$ \\
\hline Harris et al. 1966 & Laboratory & $8-22.2$ & 146.4 \\
Harukawa et al. 1934 & Laboratory & $23-8$ & 94.3 \\
Reid 1940 & Laboratory & $5-25$ & 105.5 \\
Strong and Apple 1958 & Field & $18-24$ & 100.5 \\
Yathom 1970 & Laboratory & - & 176.4 \\
\hline
\end{tabular}

${ }^{a}$ Soil-temperature based DD with a $10^{\circ} \mathrm{C}$ threshold.

class III (parous) required an additional 4 days or 66.7 DD. The sum of these periods, 6 days or 100 DD, represents the length of the SCM preovipositional period under laboratory conditions. Parous flies lived from 1 to 4 weeks, depending on temperature.

The preovipositional period in SCM has been the subject of considerable debate in the literature. Table 1 summarizes these reports and lists degreeday estimates for the length of the preovipositional period. Our laboratory estimate of $100 \mathrm{DD}\left(3.9^{\circ} \mathrm{C}\right.$ threshold) compares favorably with most previous laboratory findings. The Harris et al. (1966) study was conducted with variable temperatures, which undoubtedly prolonged ovarian development, thus explaining the greater degree-day totals reported. The totals from Yathom's (1970) study and from Reid's (1940) work at $13.7^{\circ} \mathrm{C}$ are higher than other estimates and are not as easily explained. Conceivably, nutritional deficiencies and differences in photoperiod or relative humidity in these studies might account for the differences. Alternatively, if mating is a prerequisite for ovarian development, poor mating success might also have protracted the preovipositional period in these studies. Nevertheless, approximately $100 \mathrm{DD}$ seems close to the degree-day total required for the preovipositional period. Strong and Apple's (1958) field estimate of 15.7 DD is based on soil temperatures and a $10^{\circ} \mathrm{C}$ developmental threshold. Converting to air-temperature based degree-days with a $3.9^{\circ} \mathrm{C}$ threshold could not possibly change Strong and Apple's estimate to more than 20 or $30 \mathrm{DD}$, which is still radically lower than laboratory findings.

In our field estimate of the preovipositional period, we found that 9.5 and $10 \mathrm{DD}$ (1982 and 1983 , respectively) were required for the class I to class II transition and 24 and 28 DD (1982 and 1983, respectively) for the class II to class III transition. These field results represent an average preovipositional period of $36 \mathrm{DD}$, which is comparable to that found by Strong and Apple (1958), but considerably at odds with laboratory estimates.

Age bias in the trapping technique, particularly with respect to class I flies, would explain much of this discrepancy, but evidence from trapping studies contradicts this interpretation. Many class I fe- 
males collected still had the ptilinum everted, indicating that they had very recently emerged from puparia. Similarly, if class I or class II flies were less attracted to traps than older flies, with increasing temperatures and more rapid development later in the season, fewer young flies would be captured. In fact, proportions of flies in each ovarian class were relatively consistent, by peak, throughout the season for both years.

We believe that the most reasonable explanation for differences between field and laboratory estimates of the preovipositional period is that, in the field, ambient temperatures are not the only thermal source contributing to ovarian development. Woodburn et al. (1978) demonstrated that ovarian development in the calliphorid, Lucilia cuprina (Wiedemann), is based on ambient temperatures plus a "temperature excess" proportional to direct solar radiation intensity. A similar relationship may exist for SCM.

The close agreement between our laboratory findings and those reported in the literature suggests that laboratory data represent the absolute temperature requirements for the preovipositional period. Likewise, the agreement between our field studies and those of Strong and Apple (1958) suggest that, in the field, fewer thermal units are required for ovarian development than are predicted from laboratory studies. Additional thermal unit accumulations from direct solar radiation might make up this discrepancy between laboratory and field models. Alternatively, selecting thermally favored microhabitats might also explain how SCM development in the field is more rapid than development in the laboratory. Furthermore, a significant relationship between SCM thermal accumulations and solar radiation or microhabitat affiliations might explain how SCM can be active at very low ambient temperatures.

This hypothesis implies that ovarian development has the same absolute temperature requirements in the field and laboratory. Because SCM may accumulate more thermal units than predicted from ambient temperatures, temperature requirements for ovarian development calculated from ambient temperatures are lower than absolute (laboratory) estimates.

Using this hypothesis, we can interpret our data as follows: for class I to II, an absolute temperature of $33.3 \mathrm{DD}$ is required but under most field conditions, requirement is approximately $10 \mathrm{DD}$. For class II to III, an absolute temperature of $66.7 \mathrm{DD}$ is required, but under most field conditions, requirement is approximately $26 \mathrm{DD}$.

A more quantitative explanation of SCM ovarian development with respect to ambient temperature and solar radiation requires direct experimentation, rather than extrapolation from field observations. Nevertheless, our estimates provide a basis for assigning physiological ages to each class that will be of immediate value in SCM population studies. Class I flies are from 0 to $10 \mathrm{DD}$ old (ca.
1-2 days in April and $<1$ in June for central Iowa); class II flies are between 10 and 36 DD old (ca. 46 days in April and 2-3 days in June for central Iowa); and class III flies are $>36$ DD old (ca. $>6$ days in April and $>3$ days in June for central Iowa). Probably the same number of DD for the class II to III transition (26 DD) is required for the development of each subsequent batch of eggs. These DD estimates should be interpreted as minimum ranges; unusually cool temperatures and nutritional deficiencies undoubtedly prolong development.

In the laboratory, we did not observe ovarian development unless females had been given a protein food source, which agrees with previous reports (McLeod 1964). Because the period preceding ovarian development is so brief (class I to II), females must obtain a protein meal shortly after emergence. When overwintering SCM first emerge in the spring, very few protein sources are available. Decaying vegetation is one proteinaceous food present at this time. Consequently, reports of SCM being attracted to decaying vegetation for oviposition (e.g., Hawley 1922, Miles 1948) might also be interpreted as females being attracted to a proteinaceous food.

The procedure that we have developed for SCM ovarian dissections and classifications should be of immediate practical benefit in population studies. Liu et al. (1982) point out that, by examining ovarian development, generations can be separated precisely, and that these discriminations may have direct practical applications. Similarly, by associating physiological ages with ovarian classes, SCM population age structure, as well as phenology, can be determined by using ovarian dynamics. Moreover, because predicted planting dates have been advanced as a possible management technique for SCM (Funderburk et al. 1984), detailed information on the relationship between degree-day accumulations and ovarian development, particularly the preovipositional period, will be vital in constructing a model that predicts when SCM are not ovipositing. Our approach to examining SCM ovarian dynamics, or some modification of it, might also find application among other anthomyiids, especially other Delia species.

\section{Acknowledgment}

We thank G. D. Buntin and E. S. Krafsur, Dept. of Entomology, Iowa State Univ., and J. E. Funderburk, Quincy Agric. and Educ. Center, Univ. of Florida, for their advice on the ovarian dissections and classes. This is journal paper no. J-11336 of the Iowa Agric. and Home Econ. Exp. Stn., Ames.

\section{References Cited}

Anderson, J. R. 1964. Methods for distinguishing nulliparous from parous lies and for estimating the ages of Fannia canicularis and some other cyclorrhaphous Diptera. Ann. Entomol. Soc. Am. 57: 226236. 
Funderburk, J. E., L. G. Higley, and L. P. Pedigo. 1984. Seedcorn maggot (Diptera:Anthomyiidae) phenology in central Iowa and examination of a thermal-unit system to predict development under field conditions. Environ. Entomol. 13: 105-109.

Harris, C. R., H. J. Svec, and J. A. Begg. 1966. Mass rearing of root maggots under controlled environmental conditions: seed-corn maggot, Hylemya cilicrura; bean seed fly, H. liturata; Euxesta notata; and Chaetopsis sp. J. Econ. Entomol. 59:407-410.

Harukawa, C., R. Takoto, and S. Kumashiro. 1934. Studies on the seed-corn maggot. IV. Ber. Ohara Inst. Landwirtsch. Forsch. 6: 219-253.

Hawley, I. M. 1922. Insects and other animal pests injurious to field beans in New York. N.Y. Agric. Exp. Stn. (Ithaca) Mem. 55: 943-1037.

Liu, H. J., F. L. McEwen, and G. Ritcey. 1982. Forecasting events in the life cycle of the onion maggot, Hylemya antiqua (Diptera: Anthomyiidae): application to control schemes. Environ. Entomol. 11: 751755.

McLeod, D. G. R. 1964. Nutrition and reproductive behavior of the seed-corn maggot, Hylemyia cilicrura (Rond.) (Diptera: Anthomyiidae). Entomol. Exp. Appl. 7: 329-334.

Miles, M. 1948. Field observations on the bean seed fly (seed corn maggot) Chortophila cilicrura, Rond., and C. trichodactyla Rond. Bull. Entomol. Res. 38: 559-574.

Miller, T. A., and R. E. Treece. 1968. Gonadotro- phic cycles in the face fly, Musca autumnalis. Ann. Entomol. Soc. Am. 61: 690-696.

Reid, W. J., Jr. 1940. Biology of the seed-corn maggot in the coastal plain of the south Atlantic states. U.S. Dep. Agric. Tech. Bull. 723: 1-43.

Strong, F. E., and J. W. Apple. 1958. Studies on the thermal constants and seasonal occurrence of the seedcorn maggot in Wisconsin. J. Econ. Entomol. 51: 704707.

Tyndale-Biscoe, M., and R. D. Hughes. 1969. Changes in the fernale reproductive system as age indicators in the bushfly Musca vetustissima Wlk. Bull. Entomol. Res. 59: 129-141.

Vogt, W. G., T. L. Woodburn, and M. Tyndale-Biscoe. 1974. A method of age determination in Lucilia cuprina (Wied.) (Diptera, Calliphoridae) using cyclic changes in the female reproductive system. Ibid. 64: 365-370.

Woodburn, T. L., W. G. Vogt, and R. L. Kitching. 1978. Estimation of age of females in field populations of Lucilia cuprina (Wiedemann) (Diptera: Calliphoridae) using ambient temperature and solar radiation. Ibid. 68: 251-261.

Yathom, S. 1970. A contribution to the bionomics of Hylemya platura MG. (=H. cilicrura Rond.) (Anthomyiidae) in Israel. Israel J. Entomol. 5: 177-183.

Received for publication 7 February 1984; accepted 29 May 1984. 